\title{
1 This is what we know: assessing the stock status of the data-poor 2 common sole on the Iberian coast
}

Maria Grazia Pennino ${ }^{1,2,3, *}$, Marta Cousido-Rocha ${ }^{1}$, Catarina Maia ${ }^{4}$, Alberto Rocha ${ }^{4}$, Ivone Figueiredo ${ }^{4}$, Alexandre Alonso-Fernández ${ }^{5}$, Cristina Silva ${ }^{4}$, Francisco Izquierdo ${ }^{1}$, José Castro $^{1}$, Josefina Teruel Gomez ${ }^{1}$, José Rodriguez ${ }^{1}$, Santiago Cerviño ${ }^{1}$

${ }^{1}$ Instituto Español de Oceanografía (IEO, CSIC). Centro Oceanográfico de Vigo. Subida a Radio Faro, 50-52. 36390 Vigo (Pontevedra) Spain.

${ }^{2}$ Statistical Modeling Ecology Group (SMEG). http://smeg-bayes.org

${ }^{3}$ Fishing Ecology Management and Economics (FEME) - Universidade Federal do Rio Grande do Norte - UFRN. Depto. de Ecologia, Natal (RN), Brazil.

${ }^{4}$ Instituto Português do Mar e da Atmosfera (IPMA), Av. Alfredo Magalhães Ramalho, 6, 1495-165 Lisboa, Portugal.

${ }^{5}$ Instituto de Investigaciones Marinas (IIM-CSIC), Eduardo Cabello 6, 36208 Vigo, Pontevedra, Spain.

Running head: Assessing the common sole stock status.

* Corresponding author.

E-mail address: grazia.pennino@ieo.es

\begin{abstract}
In the Iberian Coast region, the common sole (Solea solea) is considered a very relevant species due to its high commercial value. Despite its importance, the current status of this stock is still poorly known due to the scarcity of available data to apply formal assessment methods. In datapoor situations length-based methods have been widely applied to estimate biological parameters and to understand the dynamics of marine stocks. In this study we evaluate the status of common sole in the Iberian Coast region using the following three different lengthbased methods: (1) the length-based indicators, (2) the length-based spawning potential ratio and (3) the mean length-based mortality estimators. Overall, the three methods agree that this stock appears to be exploited at the maximum sustainable yield level, the immatures are well preserved whereas the proportion of large mature individuals is relatively low, although it has been increased in the last years. Assessing the status of this valuable stock through data-limited methods is the first step towards designing and implementing effective management measures.
\end{abstract}

Keywords: data-limited fisheries; stock assessment; LBI; LBSPR; Mean length Z; Solea solea 
Introduction

Sustainability refers to the ability of an exploited population to produce goods and services, including yields at adequate levels in the short term, while maintaining sufficient reproductive capacity to continue providing these goods and services in the indefinite future (Walters and Martell, 2004). Intensive exploitation and overfishing are perhaps the main threats to marine living resources. The sustainability of artisanal multi-species fisheries is a key conservation concern given its socio-economic (Chuenpagdee and Pauly, 2008; Weeratunge et al., 2014) and ecological importance, due to the significant dependence of artisanal fishers and the considerable and growing threats to coastal habitats (i.e. pollution and climate change, loss of habitats, etc.) (Halpern et al., 2015). However, insufficient and poor-quality data (i.e., lack of life-history traits, historical time series of catches structured by age, stock length distributions, fishing effort by gear and sector), prevent the application of assessment models used for many of the stocks exploited by small scale fisheries (Costello et al., 2012). Nevertheless, even with limited data, some aspects of the stock status can be inferred. In fact, data-limited assessment methods are increasingly used to assess the status of data-limited populations and provide scientific advice for their management (Carruthers et al., 2014; Dowling et al., 2019; Chrysafi and Kuparinen, 2016).

Length frequency data from commercial catches are often the most common type of data and the unique source of demographic information collected in data-limited fisheries, as they are relatively cheap and easy to collect (Pilling et al., 2009; Hordyk et al., 2015a; Mildenberger et al., 2017; Cousido-Rocha et al., submitted). As a result, numerous length-based methodologies have been developed, of which the most widely used are the Length-Based Indicators (LBI; Froese, 2004; ICES, 2015), the Length-Based Spawning Potential Ratio (LBSPR; Hordyk et al., 2015a) and the mean length-based mortality estimators (MLZ; Then et al., 2018). 
The LBI method ranks stocks according to conservation, sustainability, yield optimization and maximum sustainable yield (MSY) objectives by calculating a set of indicators based on the length composition of the catches/landings (Babcock et al., 2013; Shephard et al., 2018). LBSPR assesses stock status by the Spawning Potential ratio (SPR) defined as the proportion of Spawning Biomass per recruit (SBPR) in an exploited stock with regards to SBPR in an unfished (virgin) stock (Prince et al., 2015, 2020). MLZ estimates the year-specific total mortality rates from the annual mean lengths of fish whose lengths are larger than $\mathrm{L}_{c}$ (i.e. the length at which fish are fully vulnerable to the fishery) (Gedamke and Honenig, 2006). That is, the MLZ model requires a time series of length frequency data to define the annual mean lengths of fish fully vulnerable to the sampling gear, as well as the von Bertalanffy growth parameters. M can be obtained externally or estimated inside the model.

In the Iberian Coast region, common sole (Solea solea, Linnaeus, 1758) is targeted mainly by multi-species fleets using as main fishing gears trammel nets (Pennino et al., submitted). As mentioned above, this species has traditionally been considered of great importance due to its elevated commercial value (Teixeira et al., 2009; Teixeira and Cabral, 2010). Despite that in the North Sea the common sole stock is historically assessed and managed. In the Iberian Coast region the stock status was poorly known until recently (Tanner et al., 2017).

The management unit of the common sole stock in Iberian Atlantic waters includes both the Portuguese and Spanish fleets that operate in the International Council for the Exploration of the Sea (ICES) divisions 8c and 9a. Before 2021, this stock was classified as ICES category 5 that includes stocks for which only landings or a short series of catches are available (ICES 2021). In 2021 this stock was benchmarked, new data and models (i.e. the ones presented in this study) were presented and for this reason was upgraded to ICES category 3 that includes stocks for which survey, trends-based assessments, or other indices are available that provide reliable indications of trends in stock metrics, such as total mortality, recruitment, and biomass 
93 (ICES, 2021). Management of all sole species are made under a combined TAC which could 94 prevent effective control of the single-species exploitation rates. For the period 2011-2019, the common sole represented on average almost $60 \%$ of the total catches of sole species (ICES, 2021).

97 Catches of common sole of all gears and mesh sizes are under the Landing Obligation (LO), although discards for this species are considered negligible in the area (ICES 2019a). Overall, although some previous studies on the Portuguese flatfish fleet exist (Teixeira et al., 2009; Teixeira and Cabral, 2010), scientific studies to support an improvement of management measures are required for this stock.

102 Within this context, our study used length frequency data to evaluate the status of the common sole in the Iberian Coast region based on LBI, LBSPR and MLZ methods, which are the ones recommended by ICES to assess data-limited stocks (ICES, 2018). Assessing the status of this valuable data-limited stock is the first step towards the design and implementation of effective management measures.

108 Material and methods

\section{Common sole data}

110 Common sole length frequency distribution of commercial catches for the period 2011-2019

111 were collected by the Instituto Español de Oceanografía (IEO-CSIC) and the Instituto

112 Português do Mar e da Atmosfera (IPMA), as part of their national fishery sampling programs

113 under the European Data Collection Framework (DCF), designed to provide evidential support 114 for scientific advice regarding the Common Fisheries Policy.

115 Length frequency distribution collection in landing ports follows a stratified multistage design 116 in which the primary sampling unit is [auction*day]. The sampling design is stratified by fleet, 117 auction and quarter and sampling effort is based on the number of trips funded by the DCF 
national sampling plan. From each selected trip, length frequency distributions of every landed

119 species and commercial category are collected in a concurrent sampling scenario (Silva et al.,

120 2017). To obtain the length frequency distribution for each fishing fleet, numbers obtained at

121 each length class in the sampled trips are raised to the total landed weight by quarter (See Table

122 S1 of supplementary material for more details on the sampling network).

123 The two main fleets that catch this species in the area are (1) the Portuguese polyvalent fleet,

124 which includes coastal and local vessels with overall length ranging from 5 to $23 \mathrm{~m}$, usually

125 licensed to operate with more than one passive fishing gear (most commonly gill and trammel

126 nets, longlines and traps) that can be deployed in the same trip and target a high diversity of

127 species (Duarte et al., 2009); and (2) the Spanish artisanal fleet that catches sole mainly using

128 bottom gill and trammel nets. Both Spanish metiers are discriminated within the Spanish

129 sampling plan and data are also reported separately to the ICES assessment working groups.

130 Overall length frequency data used in the analyzes were derived from these two fleets from

131 trammel nets (98\%) and trawls (2\%) (ICES, 2021).

132 Life-history parameters required for applying length-based methods include: length at maturity

133 (Lmat, also known as L50, and L95 which are the lengths at which the probability of having

134 reached the maturity is $50 \%$ and $95 \%$, respectively), parameters of the von Bertalanffy growth

135 equation ( $K$ and $L_{\infty}$ ), ratio of natural mortality to von Bertalanffy growth rate $(M / K)$, and

136 length-weight relationship parameters ( $a$ and $b$ parameters). Length-weight relationships were

137 built using individual total length and total weight measured by observers onboard the small-

138 scale fishing fleet off NW Spain (Alonso-Fernández et al., 2021). Most of these population

139 parameters were extracted from published studies for the common sole in Portuguese waters

140 (Table 1).

141

142 Length based indicators (LBI) method 
143 The LBI method consists of several length-based indicators describing the length frequency

144 data from commercial catches, which are compared to appropriate reference points related to 145 conservation/sustainability, optimal yield and maximum sustainable yield (MSY) 146 considerations providing a description of the stock status. The indicators related to 147 conservation/sustainability can be classified in two groups: (i) conservation of large individuals 148 and (ii) conservation of immatures.

149 LBI method considers the following indicators related to (i) conservation of large individuals:

$150 \mathrm{Lmax} 5 \%$, which is the mean length of the largest 5\% of the fish, and $\mathrm{P}$ mega, which is the proportion 151 of large fish in the catch ("mega-spawners"), i.e. fish of a size larger than the optimum length $152\left(\mathrm{~L}_{\mathrm{opt}}=3 \mathrm{~L} \infty /(3+\mathrm{M} / \mathrm{K})\right)$ plus $10 \% . \mathrm{L}_{\max 5 \%}$ indicator is compared to the reference point $\mathrm{L}_{\infty}$ defining 153 the corresponding indicator ratio $\mathrm{L}_{\max 5} \% / \mathrm{L} \infty$, which provides information about the degree of 154 truncation of the population length structure that may be caused by fishing and whose expected value in healthy stocks is above 0.8 (Miethe and Dobby, 2015). Pmega follows the idea summarized by Froese (2004) as "Let the mega-spawners live" and in healthy stocks Pmega $_{\text {me }}$

157 must be above 0.3 (see Froese, 2004 and ICES, 2015).

158 The indicators related to (ii) conservation of immatures are: $\mathrm{L}_{c}$, which is the length at first 159 catch, and $\mathrm{L} 25 \%$, which is the $25^{\text {th }}$ percentile of length distribution. Both indicators are compared 160 to the reference point $\mathrm{L}_{\text {mat }}$ defining the indicator ratios $\mathrm{L}_{25} / \mathrm{L}_{\mathrm{mat}}$ and $\mathrm{L}_{\mathrm{c}} / \mathrm{L}_{\mathrm{mat}}$ that follow the 161 principle "Let them spawn" (Froese, 2004) and are expected to be higher than 1 in healthy 162 stocks.

163 Finally, LBI method considers the indicator $\mathrm{L}_{\text {mean }}$ (mean length of individuals above $\mathrm{L}_{c}$ ) and 164 compares it to the reference points $\mathrm{L}_{\text {opt }}$ and $\mathrm{LF}_{\mathrm{F}=\mathrm{M}}=(1-\mathrm{a}) \mathrm{L}_{c}+\mathrm{a} \mathrm{L}_{\infty}, \mathrm{a}=1 /(2(\mathrm{M} / \mathrm{K})+1)$, which is a 165 length-based proxy for MSY, defining the indicator ratios, $\mathrm{L}_{\text {mean }} / \mathrm{L}_{\mathrm{opt}}$ and $\mathrm{L}_{\mathrm{mean}} / \mathrm{LF}_{\mathrm{F}=\mathrm{M}}$, for 166 optimal yield and MSY considerations, respectively. Their values in healthy stocks are 
expected to be approximately 1 , for $\mathrm{L}_{\text {mean }} / \mathrm{Lopt}$, and equal or larger than 1 , for $\mathrm{L}_{\text {mean }} / \mathrm{LF}=\mathrm{M}$. Note that the indicator ratio $\mathrm{L}_{\text {mean }} / \mathrm{L}_{\mathrm{opt}}$ follows the principle "Let them grow" (Froese, 2004). As mentioned above, the LBI indicators require the length frequency data from catches/landings and the life-history parameters described in Table 1. The results derived from the application of the LBI method must be analyzed and interpreted taking into account that it assumes equilibrium conditions (constant total mortality and recruitment along the entire data time series), logistic selectivity, and that the catch length distribution is representative of the population length distribution.

\section{Length-based spawning potential ratio (LBSPR) method}

177 This approach focuses on the effect of fishing on the spawning biomass per recruit (SBPR) of the stock. It is based on the concept that without fishing, the population can reach $100 \%$ of its natural potential for spawning, but that fishing reduces the population's SBPR.

180 The SPR index ranges between 0 and 1, with a value of 1 representing an unexploited stock. It

181 is frequently assumed that stocks with a SPR range between $0.35-0.4$ could be considered exploited at MSY level (Legault and Brooks, 2013), although this is a quite variable parameter

183 (Hordyk et al., 2015b). Stocks with a SPR below 0.1-0.15 are considered close to collapse (such

184 limits have been fixed on basis on Goodyear, 1993, who pointed out that for SPR values below 1850.2 the risk of collapse increases considerably).

186 Unlike fishing mortality-based approaches, which directly relate to part of the population 187 removed each year by fishing, SPR method reflects the cumulative effect of fishing and ecological impacts on the spawning potential of exploited stocks from a few previous years (a life span period approximately). SPR can be used to set targets and limit reference points for

190 monitoring of population status. 
191 The LBSPR method estimates the SPR using the life-history parameters included in Table 1

192

193

194

195

196

197

198

199

200

201

202

203

204

205

206

207

208

209

210

211

212

213

214

215

216 and the catch length composition data. To correctly discuss the results of the LBSPR method it must be taken into account that it provides a SPR value assuming that the population is in equilibrium (as the LBI method). Furthermore, it assumes that the length frequency data is representative of the exploited population at steady state, and that the selectivity is well represented by a logistic curve. LBSPR also assumes that an overall fishing mortality rate has caused the resultant length composition, and thus it requires that length composition data comes from the dominant fleet, or that multiple fleets are combined into one composite, and a catchweighted aggregate length composition is derived.

\section{Mean length-based mortality estimators (MLZ)}

The mean length of fish that are fully vulnerable to the sampling gear can be used to estimate year-specific total mortality from basic growth parameters, a known length at first capture $\left(\mathrm{L}_{c}\right.$; length of full selectivity), and a time series of fishing effort. If natural mortality is known (or estimated, as described later), fishing mortality rates can also be calculated. This approach may in some cases represent the best opportunity to reconstruct the mortality history of a stock.

Then et al., (2018), henceforth referred to as the Then method, parameterized the annual total mortality rate as the sum of the annual fishing mortality and time and age-invariant natural mortality rate. Assuming that the fishing mortality is proportional to the fishing effort by the catchability coefficient, the catchability coefficient and the natural mortality rate are estimated based on the goodness-of-fit to the mean length data through maximum likelihood estimation. An important advantage of Then et al. (2018) method over previous proposals, as Beverton and Holt (1956, 1957) or Gedamke and Hoenig (2006), is that the use of fishing effort allows annual estimates of total and fishing mortality instead of the full period of the total mortality 
rate (Beverton and Holt, 1956, 1957) or time-blocks total mortality rates (Gedamke and

218 Hoenig, 2006).

219 The Then et al. (2018) method requires the life-history parameters in Table 1, and the so-called

220 length of first capture $L_{c}$, corresponding to the age $t_{c}$, at which animals are fully vulnerable to

221 the fishery and to the sampling gear (Gedamke and Hoenig, 2006; Then et al., 2018). Note that

222 Lc in MLZ and LBI are calculated differently. This method also uses the annual mean lengths

223 of fish larger than $L_{c}$ as input data, which are computed from the length frequency data. $L_{c}$ has

224 been calculated as the length corresponding to the peak in the histogram of the general length

225 frequency distribution, obtaining $L_{c}=30.5$. Finally, as mentioned above, the method needs a

226 time series of fishing effort, usually derived as the ratio of the catches and an index of biomass,

227 as catch per unit effort (CPUE) or landings per unit of effort (LPUE) indices. Here, the effective

228 effort of the fleet from 2011 to 2019 was calculated as the ratio of commercial landings and

229 LPUE from the Portuguese polyvalent fleet (see details in supplementary materials).

230 Additionally to the above data and input parameters, guesses for the maximum age, catchability

231 coefficient and natural mortality rate must be specified. We set the maximum age guess at 15

232 years and the catchability coefficient guess to 0.15 divided by the mean of the time series of

233 effort, being 0.15 a guess for time invariant fishing mortality, while the guess for $\mathrm{M}$ is 0.3 ,

234 according to the value in Table 1. The model also requires a specification of the fishing effort

235 prior to the first year of the mean length data which has been set equal to the fishing effort at

236 the first year of our time series.

237 The Then et al. (2018) method is based on several assumptions that must be taken into account

238 when discussing the obtained results. Such assumptions are: constant recruitment over time,

239 deterministic and time-invariant growth following a von Bertalanffy growth equation, knife- 
240 edge and time-invariant selectivity above the length of full selectivity $\left(\mathrm{L}_{c}\right)$, and known fishing

241 effort proportional to fishing mortality.

\section{Implementation and sensitivity analysis}

As mentioned above, the three methods were applied using the life-history parameters listed in

Table 1, in addition to the length frequency composition of the common sole catches. This scenario was considered as the base one used to assess the stock status of sole. However, it is important to analyze the effect of underestimation and overestimation (misspecification) of the relatively uncertain life-history parameters on the model outputs for each one of the methods.

For this reason the following sensitivity analysis has been carried out:

1. LBI method has been reapplied using underestimate and overestimate values of $\mathrm{L}_{\infty}$, $\mathrm{M} / \mathrm{K}$ and L50 parameters,

2. For the LBSPR method the same analysis has been carried out considering the parameters $\mathrm{L}_{\infty}, \mathrm{M} / \mathrm{K}$ and $\mathrm{L}_{50}, \mathrm{~L} 95$,

3. For the MLZ method the sensitivity to the misspecification of $\mathrm{L}_{\infty}, \mathrm{K}$ and $\mathrm{L}_{\mathrm{c}}$ parameters has been analyzed. Additionally, the sensitivity of the model outputs to the guesses of maximum age (max A) and catchability coefficient (q) has also been addressed.

The lower and upper bounds for each of the mentioned parameters was a reduction and an increase by 10 and $20 \%$ on the base value in Table 1 , except for $L_{c}$ where the percentage of change has been reduced to $5 \%$ as the increase of 10 or $20 \%$ on the base value of $L_{c}=30.5$ is too high according to the annual mean lengths values. The MLZ method has been adjusted, both in the base setting and in the sensitivity analysis scenarios, without fixing a natural mortality rate obtained from external sources. Therefore, for comparative purposes the MLZ method has been reapplied in the base setting fixing $M$ equal to the value given in Table 1 . 
265 All the statistical analyses were performed using R programming language (R Development 266 Core Team, 2021). The LBI method was fitted using the R code available at ICES Tools

267 (development area) Github (https://raw.githubusercontent.com/ices-tools-

268 dev/LBIndicator_shiny/master/utilities.R); LBSPR method was implemented using the

269 LBSPR package (Hordyk, 2019) and MLZ method was implemented using the Then et al.

270 (2018) method, whose $\mathrm{R}$ code is available at https://github.com/ices-tools-

271 dev/ICES_MSY/tree/master/R.

272 All the R code implemented in this study can be found as open-access source in the GitHub

273 repository (https://github.com/IMPRESSPROJECT/assessing-the-stock-status-of-the-data-

274 poor-common-sole-8c9a).

275

276

277

278

279

280

281

282

283

284

285

286

287

\section{Results}

The length frequency distribution was consistent along the entire time series, with a mode around $30 \mathrm{~cm}$ (Figure 1), showing overall an unimodal distribution.

\section{Length based indicators (LBI) method}

Time-series of LBI derived from the base model suggest that the common sole showed a generally improving state (Table 2 and Figure 2). Most indicators received a consistently good evaluation, except for $\mathrm{P}_{\text {mega, }}$ which represents the proportion of the mega-spawners with 0.3 as a target. Indeed, from the base model we can conclude that the stock is exploited at MSY level and the optimal yield is attained. The conservation of immature individuals is achieved whereas the proportion of mega-spawners is low, although it has increased in the last few years. Note that although the values of MSY and of the maturity conservation indicators (i.e., $\mathrm{L}_{\mathrm{c}} / \mathrm{L}_{\mathrm{mat}}$, 
$293 \mathrm{~L} 25 \% / \mathrm{Lmat}$ ) are below the expected value of 1 for some years, these values are very close to this

294 reference value.

295 The sensitivity analysis shows that the overestimation of $\mathrm{M} / \mathrm{K}$ and the underestimation of $\mathrm{L}_{\infty}$

296 and L50 leads to a more optimistic perception of the state of stock, and vice versa (Figure 3 and

297 Figure S4). As we expected, by definition, there is no impact of underestimation or

298 overestimation of $\mathrm{L}_{\infty}$ on the $\mathrm{Lc} / \mathrm{L}$ mat and $\mathrm{L}_{25} / \mathrm{L}$ mat indicators in both scenarios (10 and 20\%).

299 Among the indicator ratios for which misspecification of parameter $\mathrm{L} \infty$ has an effect $\left(\mathrm{L}_{\mathrm{mean}} / \mathrm{L}_{\mathrm{opt}}\right.$,

$300 \mathrm{~L}$ mean $/ \mathrm{LF}_{\mathrm{F}} \mathrm{M}, \mathrm{P}_{\text {mega }}$ and $\left.\mathrm{L}_{\max 5 \%} / \mathrm{L} \infty\right), \quad \mathrm{P}_{\text {mega }}$ reports the highest mean ratios change for

301 underestimation and overestimation of $\mathrm{L}_{\infty}$. For both scenarios (10 and 20\%), Figure 3 and

302 Figure S4, combined with Table 2, shows that the magnitude of the annual average of changes

303 in ratios are not large enough to lead to different final conclusions on the stock status, with the

304 exception of $P_{\text {mega }}$ which increases attaining values above the threshold of 0.3 for

305 underestimation of $\mathrm{L}_{\infty}$ giving the perception that mega-spawners would be well preserved. In

306 the sensitive analysis of the $\mathrm{M} / \mathrm{K}$ parameter, the magnitude of the annual average of the ratio

307 change is lower than the corresponding one in the $\mathrm{L}_{\infty}$ study, suggesting that the Lo parameter

308 is more relevant in the method computation than $\mathrm{M} / \mathrm{K}$ (Figure 3 and Figure S4). The

309 misspecification of M/K affects $\mathrm{P}_{\text {mega, }}$ optimal yield and MSY indicators. The greatest mean

310 ratio change corresponds to $\mathrm{P}_{\text {mega }}$ with overestimation of $\mathrm{M} / \mathrm{K}$ where values were increased

311 being larger or close to the threshold of 0.3 , whereas the small differences among 1 and the

312 mean ratios change of the remaining indicators lead to the conclusions about the stock status

313 derived from the base model.

314 Finally, the sensitivity analysis of the L50 shows that the underestimation or overestimation of

315 this parameter only affects the indicator ratios related to the conservation of immature

316 individuals, $\mathrm{Lc} / \mathrm{Lmat}$ and $\mathrm{L} 25 \% / \mathrm{Lmat}$. The decreasing of such indicator ratios under overestimation 
317 L50 is not disturbing since the differences among 1 and the annual average of ratios change are 318 slight.

319 Summarizing, the sensitive analysis supports the conclusion of a generally improving state of 320 common sole derived from the base LBI application.

\section{Length-based spawning potential ratio (LBSPR) method}

324 The results of the LBSPR method in the base parameter configuration suggested that the common sole has been exploited at MSY level (Figure 4), agreeing with the LBI indicators. Along the time series, SPR values vary between 0.28 and 0.41 , which is around the expected range for a healthy stock. Moreover, it is worth noting that the SPR shows an increasing trend over time, with the higher values of 0.38 and 0.41 occurring in the last two years of the time series. According to that, a decreasing trend can be observed on the F/M values. Changes in the selectivity estimates are minimal, which is the expected behaviour taking into account that there were no reasons to think that the fishing fleet selectivity has evolved significantly along the study period.

333 The main conclusions match those exposed previously for the LBI method. That is, the overestimation of $\mathrm{M} / \mathrm{K}$ and the underestimation of $\mathrm{L}_{\infty}$ and $\mathrm{L}_{50}$ and $\mathrm{L}_{95}$ leads to a more optimistic perception of the stock status, and vice versa (Figure 4, 5, S5 and S6). Furthermore, the results

336 show that the accuracy of the Lo $_{\infty}$ parameter is crucial in the LBSPR method since its underestimation and overestimation leads to very different results. In spite of this, it is worth

338 mentioning that with the $10 \%$ scenario even under the overestimation of the $\mathrm{L}_{\infty}$ (the most pessimistic setting) the corresponding SPR values are above the thresholds associated with a

340 collapsed stock. On the contrary in the $20 \%$ scenario, values are close to the thresholds of a

341 collapsed stock for some years, but not in the most recent ones (Figure S5 and S6). 
342 The parameters M/K, L50 and L95 also have an effect on the results but in a softer manner,

343 leading to a similar perception of the stock status as in the base setting.

\section{Mean length-based mortality estimators (MLZ)}

347 The effective effort showed a sharp increase in 2012 followed by a strong decrease in the

348 following year (Figure 6). In the base model, the fishing mortality estimates range from 0.20 to 0.15 showing a decreasing pattern (Figure 7). The year 2012 was the year with the highest fishing mortality estimate $(F=0.22)$, while 2013 was the one with the lowest value $(F=0.14)$. Furthermore, Figure 7 also includes horizontal lines representing $F_{\max }$, the value of fishing mortality that produces maximum YPR (Yield-per-Recruit), and $\mathrm{F}_{0.1}$, the value of fishing mortality at which the slope of the YPR curve is reduced to 0.1 of the slope estimated at the origin. Both reference points have been computed using the YPR analysis implemented in

$\mathrm{b}$ in Table $1, \mathrm{t}_{0}=-0.15$ (hypothetical age at which the species has zero length) and $\mathrm{M}=0.31$.

The $\mathrm{F}$ estimates for all the scenarios are below $F_{\max }$, and furthermore only for the overestimation of $\mathrm{L}_{\mathrm{c}}$ parameter in both scenarios (10 and 20\%) the F estimates are above the reference of $\mathrm{F}_{0.1}$.

360 The fits to the mean length data were similar regardless of whether $\mathrm{M}$ was estimated or fixed 361 (Figures 7, 8, S7 and S8). With $\mathrm{M}$ fixed at 0.31, the estimated values of $\mathrm{F}$ were lower, reaching 0.20 in 2012 and decreasing to 0.12 in 2013.

363 Figures 7, 8 and S7 and S8 show that the MLZ outputs are not sensitive to the guesses of

364 maximum age (max A) and catchability coefficient (q). A slight reduction and increase in the

$365 \quad \mathrm{~F}$ and q estimates was predicted by the model runs during the time series concurrent with the increase and decrease in the K, nevertheless the differences among 1 and the annual average of 
change ratios are soft as well (Figure 8 and S8). On the contrary, M estimates are almost not affected by the $\mathrm{K}$ variation.

369 As in previous methods, the crucial parameters are $\mathrm{L}_{c}$ and $\mathrm{L}_{\infty}$ leading to a more pessimistic perception of the stock when they are overestimated. Although the estimates of fishing mortality undergo significant changes when $\mathrm{L}_{c}$ or $\mathrm{L}_{\infty}$ values are modified, it is important to stand out that the temporal decreasing trends of the $\mathrm{F}$ is maintained in all the settings. Therefore, the conclusion of a reduction in the fishing mortality rates is consistent over all the settings in spite of the fact that the values of $\mathrm{F}$ can change substantially under overestimation or underestimation of $\mathrm{L}_{c}$ or $\mathrm{L}_{\infty}$.

\section{Discussion}

This study shows that, across the most plausible range of life history parameters, the common

380 sole stock of the ICES divisions 8c and 9a seems to be exploited at MSY level. Using a 9-year time series of catch data, reference points for length-based assessment were obtained. LBI estimated indicator values are reasonable and traffic light assessment outcomes reflect that the conservation of immatures is achieved in this stock whereas the proportion of large mature individuals is low, although it has been increased in the last years. This result could also reflect the selectivity pattern of the artisanal fleet that operates in shallower waters where larger individuals are scarce. Indeed, the expectation of $\mathrm{P}_{\text {mega }}>0.3$ (LBI method) assumes asymptotic selection; if the selection is dome-shaped, we must take into account that lower values of Pmega are desirable following the fishing strategy that no mega-spawners are caught (Shepard et al., 2018). This could be the case of the common sole fisheries which are mainly conducted with

390 gillnets with dome-shaped selectivity. Cope and Punt (2009), also conclude that $\mathrm{P}_{\text {mega }}$ showed a wide range of possible values depending on fishery selectivity. 
392 SPR is defined as the proportion (or rate) of the unfished reproductive population left after exploitation by a fishery and is generally used to set target and limit reference points for fisheries management in data-limited fisheries (Hordyk, 2019). Based on the definition of spawning potential ratio (SPR), unfished stocks have an SPR of 100\% (SPR100\%). Fishing mortality reduces SPR100\% from the unfished level to SPRX\% (Suryandari, 2018). Scenarios analysed in this study resulted in a mean SPR value of 35\%. The reference limit of SPR 35$40 \%$ is generally considered a conventional substitution for MSY (Legault and Brooks, 2013).

This indicates that the common sole stock is in a healthy status, with a good proportion of individuals remaining to spawn. However it is worth to be mentioned that the deviation from certain assumptions can lead to a bias in the final estimates. For instance, according to Hordyk et al., (2015b), the LBSPR slightly underestimates the SPR for populations caught with gill nets (their selectivity curve is dome-shaped) as in the case of the Portuguese polyvalent fleet. The MLZ showed that the fishing mortality is decreasing for this stock in recent years. This trend could also be related to the fact that a precautionary TAC reduction of $20 \%$ was applied to fishing opportunities in 2013 and again in 2018. This catch reduction was suggested because this stock was classified as category 5 within the ICES framework, which means that no information on abundance or exploitation was available (ICES, 2012). In these cases ICES considers that a precautionary approach should be implemented. Indeed, scientific studies to underpin an improvement of management measures for this stock are scarce and do not reflect

411 the importance of this resource. Although some regulations exist concerning Total Allowable

412 Catches (TAC) based on the landings trend, fishing quotas and MCRS (Minimum Conservation

413 Reference Size) the common sole stock has not been quantitatively assessed until the moment.

414 Various authors have found that estimates of the parameters $q$ and $\mathrm{M}$ are highly negatively 415 correlated when estimated within a common model framework (e.g. Megrey, 1988; Wang, 416 1999; Fu and Quinn II, 2000). These parameters are also difficult to estimate reliably when 
417 there is little contrast in the catch or effort data. Here, due to the data-limited situation of this

418 stock where the time series is very short (only 9-years were available to perform the study), a

419 lack of contrast in both catch and effort could be possible.

420 In the absence of direct fishing effort data, one could estimate effort from total commercial 421 catch. In practice, it may be difficult to obtain a time series of standardized fishing effort 422 because of multiple and changing fishing gears. Indeed, in our case only one LPUE time series 423 was available from Portugal and no effort was introduced for Spain. However, the Portuguese polyvalent fleet from which the LPUE was derived is the main fleet that catches this stock and for this reason was considered representative.

A comparison of our results to those of other studies is hampered by the limited amount of research that has been conducted on the dynamics of common sole populations in the Iberian Coast region. Nevertheless, recent studies on the relative abundance indices and body size trends of coastal species in the Northwestern of the Iberian peninsula suggest a relatively stable scenario (without sign of undesirable patterns) of the status of the S. solea stock exploited by small-scale fisheries (Alonso-Fernández et al., 2019; 2021).

The other stocks of $S$. solea in the surrounding areas, as those from the ICES divisions 7.e (western English Channel), 7.f and 7.g (Bristol Channel, Celtic Sea) and 8.a and 8.b (northern and central Bay of Biscay), showed healthy stock status in all the reference points relative to the fishing pressure (i.e., $\mathrm{F}_{\mathrm{msy}}, \mathrm{F}_{\mathrm{pa}}$, $\mathrm{F}_{\text {lim }}$ and $\mathrm{F}_{\mathrm{mgt}}$ ) and stock size (i.e., $\mathrm{B}_{\text {trigger, }} \mathrm{B}_{\mathrm{pa}}, \mathrm{B}_{\text {lim }}$ and Bmgt) (ICES, 2019b; ICES, 2019c; ICES, 2020).

437 Our sensitivity analysis has been performed examining the effects of misspecification/variation of the crucial parameters of the three implemented methods. The effects of inaccuracy in input parameters should be taken into account when drawing conclusions about stock status to avoid 440 further failures in actual management. Through our study we came to the conclusion that the 441 influence of the variation in the parameters of the input life history is of great importance in all 
442 the methods. More precisely, we state that different management decisions can be drawn when

443 the crucial parameter $\mathrm{L}_{\infty}$ is underestimated or overestimated by $10 \%$. According to Shephard

444 et al., (2018) we concluded that an unrealistically high $\mathrm{L}_{\infty}$ could generate false negatives (a

445 poor state result when the true state is good), while a low Lo could generate false positives (a

446 good state result when the true state is bad). Best practices for determining fixed values for life

447 cycle parameters in stock assessment would use estimates from specific stock studies (Rudd et

448 al., 2019). However, when such studies are not available, our practical recommendation is to

449 perform a sensitive analysis on these parameters.

450 Although there is some variability and uncertainty in the results of our study, the pattern of 451 exploitation appears to be clear and consistent. Given the data available, the 3 methods 452 analyzed show a general agreement in the results on stock and exploitation status strengthening 453 our conclusions. More and better data are required to conduct a proper assessment (Dowling et 454 al., 2019); nevertheless, the present study shows no evidence that the common sole population 455 in the Iberian Coast region is experiencing high levels of mortality or is currently under any threat. It should be noted, however, that the results of our study apply only to the specific studied area and that the time series available is considerably short. Thus, further research will be needed to complement our study and improve our understanding of this stock.

460 Acknowledgments

461 This study is a contribution to the project IMPRESS (RTI2018-099868-B-I00), ERDF, 462 Ministry of Science, Innovation and Universities - State Research Agency and also of GAIN 463 (Xunta de Galicia), GRC MERVEX (n IN607-A 2018-4). 
Alonso-Fernández, A., Otero, J., Bañón, R., Campelos, J. M., Quintero, F., Ribó, J., ... \& Molares, J. (2019). Inferring abundance trends of key species from a highly developed smallscale fishery off NE Atlantic. Fisheries Research, 209, 101-116. https://doi.org/10.1016/j.fishres.2018.09.011

Alonso-Fernández, A., Otero, J., \& Bañón, R. (2021). Indicators of body size variability in a highly developed small-scale fishery: Ecological and management implications. Ecological 475 Indicators, 121, 107141. https://doi.org/https://doi.org/10.1016/j.ecolind.2020.107141

Babcock, E. A., Coleman, R., Karnauskas, M., \& Gibson, J. (2013). Length-based indicators of fishery and ecosystem status: Glover's Reef Marine Reserve, Belize. Fisheries Research, $147,434-445$. https://doi.org/https://doi.org/10.1016/j.fishres.2013.03.011

Beverton, R. J. H. (1956). A review of methods for estimating mortality rates in fish populations, with special reference to sources of bias in catch sampling. Rapp Proces-verb Reun Cons Int Explor Mer, 140, 67-83.

Beverton, R. J. H. (1957). On the dynamics of exploited fish populations, ministry of agriculture, fisheries and food (London). Fish. Invest. Ser. 2, 19, 553.

487

Carruthers, T. R., Punt, A. E., Walters, C. J., MacCall, A., McAllister, M. K., Dick, E. J., \& Cope, J. (2014). Evaluating methods for setting catch limits in data-limited fisheries. Fisheries Research, 153, 48-68. https://doi.org/10.1016/j.fishres.2013.12.014

Cerim, H., \& Ateş, C. (2020). Age, growth and length-weight relations of common sole (Solea solea Linnaeus, 1758) from Southern Aegean Sea. Aquatic Sciences and Engineering, 35(2), 36-42. https://doi.org/10.26650/ASE2020596672

496 Chuenpagdee, R., \& Pauly, D. (2008). Small is beautiful? A database approach for global assessment of small-scale fisheries: preliminary results and hypotheses. In American Fisheries Society Symposium, 49 (1): 575.

Cope, J. M., \& Punt, A. E. (2009). Length-based reference points for data-limited situations: applications and restrictions. Marine and Coastal Fisheries: Dynamics, Management, and Ecosystem Science, 1(1), 169-186. https://doi.org/10.1577/C08-025.1

Costello, C., Ovando, D., Hilborn, R., Gaines, S. D., Deschenes, O., \& Lester, S. E. (2012).

506 Status and solutions for the world's unassessed fisheries. Science, 338(6106), 517-520.

507 [Under review] Cousido-Rocha, M., Cerviño, S., Alonso.Fernández, A., Gil. J., González 508 Herraiz, I., Rincón, M. M., Ramos, F., Rodríguez-Cabello, C., Sampedro, P., Vila, Y., and 509 Grazia Pennino, M. Applying length-based assessment methods to fishery resources of 
the Bay of Biscay and Iberian Coast ecoregion: stock status and parameter sensitivity. Fisheries

511 Research, submitted.

513 Dowling, N. A., Smith, A. D., Smith, D. C., Parma, A. M., Dichmont, C. M., Sainsbury, K.,

514 \& Cope, J. M. (2019). Generic solutions for data-limited fishery assessments are not so

515 simple. Fish and Fisheries, 20(1), 174-188.

516 https://doi.org/ 10.1111/faf.12329

517

518

Duarte, R., Azevedo, M., \& Afonso-Dias, M. (2009). Segmentation and fishery characteristics of the mixed-species multi-gear Portuguese fleet. ICES Journal of Marine Science, 66(3), 594606. https://doi.org/10.1093/icesjms/fsp019

Froese, R. (2004). Keep it simple: three indicators to deal with overfishing. Fish and Fisheries, 5 (1), 86-91. https://doi.org/10.1111/j.1467-2979.2004.00144.x

Gedamke, T., \& Hoenig, J. M. (2006). Estimating mortality from mean length data in nonequilibrium situations, with application to the assessment of goosefish. Transactions of the American Fisheries Society, 135(2), 476-487. https://doi.org/10.1577/T05-153.1

Goodyear, C. P. (1993). Spawning stock biomass per recruit in fisheries management: foundation and current use. Canadian Special Publication of Fisheries and Aquatic Sciences, 67-82.

Halpern, B.S., Frazier, M., Potapenko, J., Casey, K.S., Koenig, K., Longo, C., Lowndes, J.S., Rockwood, R.C., Selig, E.R., Selkoe, K.A. (2015). Spatial and temporal changes in cumulative human impacts on the world's ocean. Nature Communications, 6, 7615.

Hordyk, A. (2019). LBSPR: An R package for simulation and estimation using life-history ratios and length composition data. URL https://github. com/AdrianHordyk/LBSPR.

https://github. com/AdrianHordyk/LBSPR, 2019

Hordyk, A., Ono, K., Valencia, S., Loneragan, N., \& Prince, J. (2015a). A novel length-based empirical estimation method of spawning potential ratio (SPR), and tests of its performance, for small-scale, data-poor fisheries. ICES Journal of Marine Science, 72(1), 217-231. https://doi.org/10.1093/icesjms/fsu004

Hordyk, A. R., Loneragan, N. R., \& Prince, J. D. (2015b). An evaluation of an iterative harvest strategy for data-poor fisheries using the length-based spawning potential ratio assessment methodology. Fisheries Research, 171, 20-32. https://doi.org/10.1016/j.fishres.2014.12.018

Huynh, Q. C., Cummings, N. J., \& Hoenig, J. M. (2020). Comparisons of mean length-based mortality estimators and age-structured models for six southeastern US stocks. ICES Journal of Marine Science, 77(1), 162-173.

https://doi.org/10.1093/icesjms/fsz191 
ICES. 2012. Report of the Workshop on the Development of Assessments based on LIFE history traits and Exploitation Characteristics (WKLIFE), 13-17 February 2012, Lisbon, Portugal . ICES CM 2012/ACOM:36. 140 pp.

ICES (2015). Report of the fifth Workshop on the development of quantitative assessment methodologies based on life-history traits, exploitation characteristics and other relevant parameters for data-limited stocks (WKLIFE V). Lisbon, Portugal. http://ices.dk/sites/pub/Publication\%20Reports/Expert\%20Group\%20Report/acom/2015/WK

ICES (2018). Technical Guidelines - ICES reference points for stocks in categories 3 and 4. ICES Technical Guidelines. https://doi.org/10.17895/ices.pub.4128

ICES (2019a). Advice basis. In Report of the ICES Advisory Committee, 2019. ICES Advice 2019, section 1.2. https://doi.org/10.17895/ices.advice. 5757

ICES (2019b). Sole (Solea solea) in Division 7.e (western English Channel). In Report of the ICES Advisory Committee, 2019. ICES Advice 2019, sol.27.7e. https://doi.org/10.17895/ices.advice.4804

ICES (2019c). Sole (Solea solea) in divisions 8.a-b (northern and central Bay of Biscay). In Report of the ICES Advisory Committee, 2019. ICES Advice 2019, sol.27.8ab. https://doi.org/10.17895/ices.advice.4775

ICES (2020) Sole (Solea solea) in divisions 7.f and 7.g (Bristol Channel, Celtic Sea). In Report of the ICES Advisory Committee, 2020. ICES Advice 2020, sol.27.7fg. ices.dk/sites/pub/Publication Reports/Advice/2020/2020/sol.27.7fg.pdf

ICES (2021) Sole (Solea solea) in divisions 8.c and 9.a (Cantabrian Sea and Atlantic Iberian waters). In Report of the ICES Advisory Committee, 2021. ICES Advice 2021, sol.27.8c9a, https://doi.org/10.17895/ices.advice.8528.

Jardim, E., R. Alpoim, C. Silva, A.C. Fernandes, C. Chaves, M. Dias, N. Prista, A.M. Costa. 2011. Portuguese data provided to WGHMM for stock assessment in 2011. Working Document presented at the ICES Working Group on the Assessment of Southern Shelf Stocks of Hake, Monk and Megrim (WGHMM), 5-11 May 2011, ICES Headquarters, Copenhagen, Denmark. ICES CM 2011/ACOM: 11, 625 pp.

Legault, C. M., \& Brooks, E. N. (2013). Can stock-recruitment points determine which spawning potential ratio is the best proxy for maximum sustainable yield reference points?. ICES Journal of Marine Science, 70(6), 1075-1080.

https://doi.org/10.1093/icesjms/fst105

Miethe, T., \& Dobby, H. (2015). Selection of length-based indicators for shellfish stocks and fisheries. Working Document, ICES report WKLIFE V 2015 ICES CM 2015/ACOM: 56.

Mildenberger, T. K., Taylor, M. H., \& Wolff, M. (2017). TropFishR: an R package for fisheries analysis with length-frequency data. Methods in Ecology and Evolution, 8(11), 1520-1527. https://doi.org/10.1111/2041-210X.12791 
609 [Under review] Pennino, M.G., Izquierdo, F., Paradinas, I., Cousido, M., Velasco, F., \& 610 Cerviño, S. Identifying persistent abundance areas: the case study of the common sole in the northern Iberian waters. Fisheries Research

Pilling, G. M., Apostolaki, P., Failler, P., Floros, C., Large, P. A., Morales-Nin, B. \& Tsikliras, A. C. (2009). Assessment and management of data-poor fisheries. Advances in fisheries science, 50, 280-305.

616

617 Prince, J., Victor, S., Kloulchad, V., \& Hordyk, A. (2015). Length based SPR assessment of 618 eleven Indo-Pacific coral reef fish populations in Palau. Fisheries Research, 171, 42-58.

Prince, J., Creech, S., Madduppa, H., \& Hordyk, A. (2020). Length based assessment of spawning potential ratio in data-poor fisheries for blue swimming crab (Portunus spp.) in Sri Lanka and Indonesia: Implications for sustainable management. Regional Studies in Marine Science, 36, 101309.

https://doi.org/10.1016/j.rsma.2020.101309

Rudd, M. B., Thorson, J. T., \& Sagarese, S. R. (2019). Ensemble models for data-poor assessment: accounting for uncertainty in life-history information. ICES Journal of Marine Science, 76(4), 870-883.

https://doi.org/10.1093/icesjms/fsz012

Silva, C., Azevedo, M., Chave,s C., Coelho, R., Costa, A.M.C., Dinis, D., Dores, S., Fernandes, A.C.F., Gonçalves, P., Lino, P.G., Mendes, H., Moura, T., Nunes, C., Oroszlányová, M., Pinto, D., \& Silva, M.C. (2017). Report of the Workshop on Sampling Effort for Biological Parameters (WKSEBP), IPMA, Lisbon 18 - 20 April. Relat. Cient. Téc. do IPMA (http://ipma.pt), $\mathrm{n}^{\circ} 17,55 \mathrm{p}+4$ Anexos.

Shephard, S., Davidson, I. C., Walker, A. M., \& Gargan, P. G. (2018). Length-based indicators and reference points for assessing data-poor stocks of diadromous trout Salmo trutta. Fisheries research, 199, 36-43.

https://doi.org/https://doi.org/10.1016/j.fishres.2017.11.024

Suryandari, A. (2018). Life history and stock status of scalloped spiny lobster (Panulirus homarus) in Prigi Bay, East Java Province, Indonesia: analysing the potential for stock enhancement. United Nations University Fisheries Training Programme, Iceland final project. http://www.unuftp.is/static/fellows/document/Astri17prf.pdf

Tanner, S. E., Teles-Machado, A., Martinho, F., Peliz, Á., \& Cabral, H. N. (2017). Modelling larval dispersal dynamics of common sole (Solea solea) along the western Iberian coast. Progress in Oceanography, 156, 78-90.

https://doi.org/10.1016/j.pocean.2017.06.005

Teixeira, C. M., \& Cabral, H. N. (2010). Comparative analysis of the diet, growth and reproduction of the soles, Solea solea and Solea senegalensis, occurring in sympatry along the Portuguese coast. Journal of the Marine Biological Association of the United Kingdom, 90(5), 995-1003. https://doi.org/10.1017/S0025315410000238 
Teixeira, C. M., Pinheiro, A., \& Cabral, H. N. (2009). Feeding ecology, growth and sexual

660 cycle of the sand sole, Solea lascaris, along the Portuguese coast. Journal of the Marine

661 Biological Association of the United Kingdom, 89(3), 621-627. https://doi.org/10.1017/S0025315409002562

Then, A. Y., Hoenig, J. M., \& Huynh, Q. C. (2018). Estimating fishing and natural mortality rates, and catchability coefficient, from a series of observations on mean length and fishing

Science, $\quad 75(2)$, 610-620.

668

669

670

671

672

673

674

675

676

677

678

679

680

681

682

683

684

685

686 https://doi.org/10.1093/icesjms/fsx177

Walters, C.J. \& Martell, S.J.D. (2004) Fisheries Ecology and Management. Princeton, NJ, USA: Princeton University Press: 399 pp.

Weeratunge, N., Béné, C., Siriwardane, R., Charles, A., Johnson, D., Allison, E. H., \& Badjeck, M. C. (2014). Small-scale fisheries through the wellbeing lens. Fish and Fisheries, 15(2), 255279. https://doi.org/10.1111/faf.12016

\section{Tables}

Table 1: Life history parameters ( $\mathrm{L}_{\infty}, \mathrm{L} 50, \mathrm{~L} 95, \mathrm{M} / \mathrm{K}, \mathrm{K}$ and $a$ and $b$ ) for the common sole (Solea solea) stock and the corresponding source of information. For each of the length based methods (LBI, LBSPR and MLZ) we specify which of the life history parameters are required.

\begin{tabular}{|l|l|l|c|c|c|}
\hline Parameters & Value & Source & \multicolumn{3}{|c|}{ Methods } \\
\hline $\mathrm{L}_{\infty}$ & $48.9 \mathrm{~cm}$ & $\begin{array}{l}\text { ICES stock } \\
\text { annex S. solea } \\
\text { divisions 8c9a }\end{array}$ & $\checkmark$ & $\checkmark$ & $\checkmark$ \\
\hline L50 & $26 \mathrm{~cm}$ & $\begin{array}{l}\text { Jardim et } \\
\text { al., (2011) }\end{array}$ & $\checkmark$ & $\checkmark$ & \\
\hline L95 & $27.5 \mathrm{~cm}$ & $\begin{array}{l}\text { ICES stock } \\
\text { annex S. solea } \\
\text { divisions 8ab }\end{array}$ & & $\checkmark$ & \\
\hline $\mathrm{M} / \mathrm{K}$ & 1.41 & $\begin{array}{l}\text { Cerim et al. } \\
\text { (2020) and } \\
\text { Teixeira and } \\
\text { Cabral (2010) }\end{array}$ & $\checkmark$ & $\checkmark$ & \\
\hline $\mathrm{K}$ & 0.22 & $\begin{array}{l}\text { Teixeira and } \\
\text { Cabral (2010) }\end{array}$ & & & \\
\hline$a$ and $b$ & $\begin{array}{l}a=0.009476898 ; \\
b=3.018329\end{array}$ & $\begin{array}{l}\text { Alonso- } \\
\text { Fernández et } \\
\text { al., 2021 }\end{array}$ & & $\checkmark$ & \\
\hline
\end{tabular}


690

691

\begin{tabular}{|c|c|c|c|c|c|c|}
\hline & \multicolumn{4}{|c|}{ Conservation } & \multirow{2}{*}{$\begin{array}{l}\text { Optimizing } \\
\text { Yield } \\
\text { Lmean/Lopt }\end{array}$} & \multirow{2}{*}{$\begin{array}{l}\text { MSY } \\
\text { Lmean/LF=M }\end{array}$} \\
\hline Year & Lc/Lmat & $\mathrm{L} 25 \% / \mathrm{Lmat}$ & $\mathrm{Lmax} 5 \% / \mathrm{L} \infty$ & Pmega & & \\
\hline $\begin{array}{l}\text { Expected } \\
\text { value }\end{array}$ & $>1$ & $>1$ & $>0.8$ & $>0.3$ & $\approx 1$ & $\geq 1$ \\
\hline 2011 & 1.10 & 1.10 & 0.94 & 0.13 & 1.00 & 0.99 \\
\hline 2012 & 0.83 & 1.02 & 0.90 & 0.17 & 0.96 & 1.12 \\
\hline 2013 & 1.02 & 1.10 & 0.89 & 0.14 & 0.99 & 1.01 \\
\hline 2014 & 1.02 & 1.10 & 0.91 & 0.15 & 0.99 & 1.02 \\
\hline 2015 & 1.06 & 1.10 & 0.88 & 0.12 & 0.98 & 0.98 \\
\hline 2016 & 0.87 & 0.98 & 0.93 & 0.17 & 0.95 & 1.08 \\
\hline 2017 & 1.10 & 1.13 & 0.91 & 0.15 & 1.02 & 1.00 \\
\hline 2018 & 1.02 & 1.10 & 0.93 & 0.18 & 1.00 & 1.03 \\
\hline 2019 & 1.13 & 1.17 & 0.94 & 0.23 & 1.05 & 1.01 \\
\hline
\end{tabular}

692

693

694

695

696

697

698

699

700

701

702

703

704

705

706

707

708

709

710

Table 2: Traffic light indicator table for the LBI analysis.

Table 2: Traffic light indicator table for the LBI analysis. 
711

712

713

714
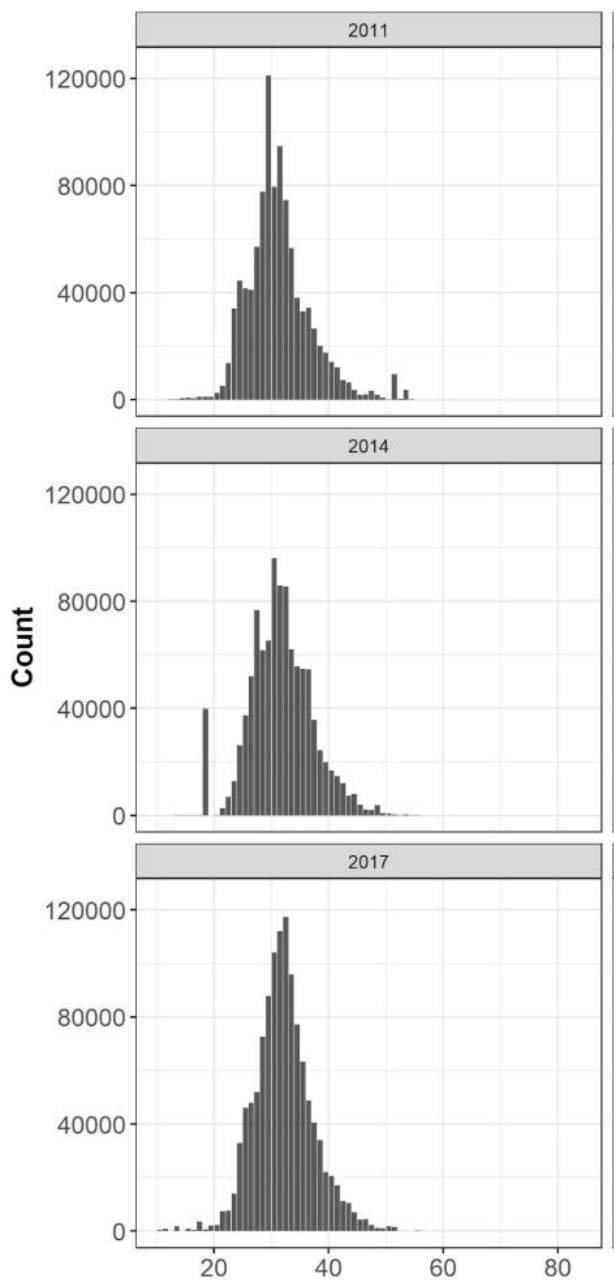

715

716

717

718

719

720

721

722

723

724

725

726

727

728

729

730

731

732

733
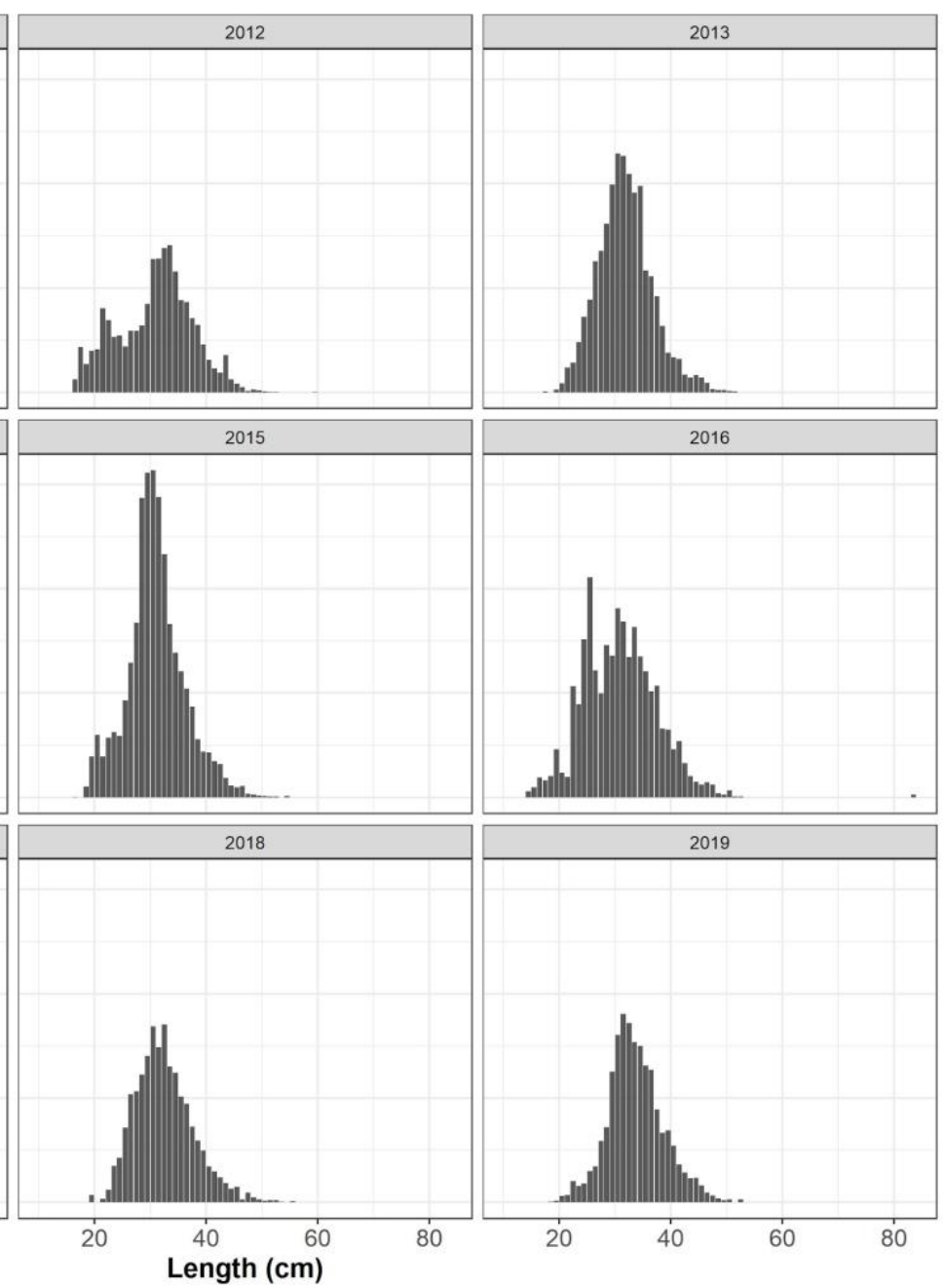

Figure 1: Length frequency composition of the common sole catches from 2011-2019. 


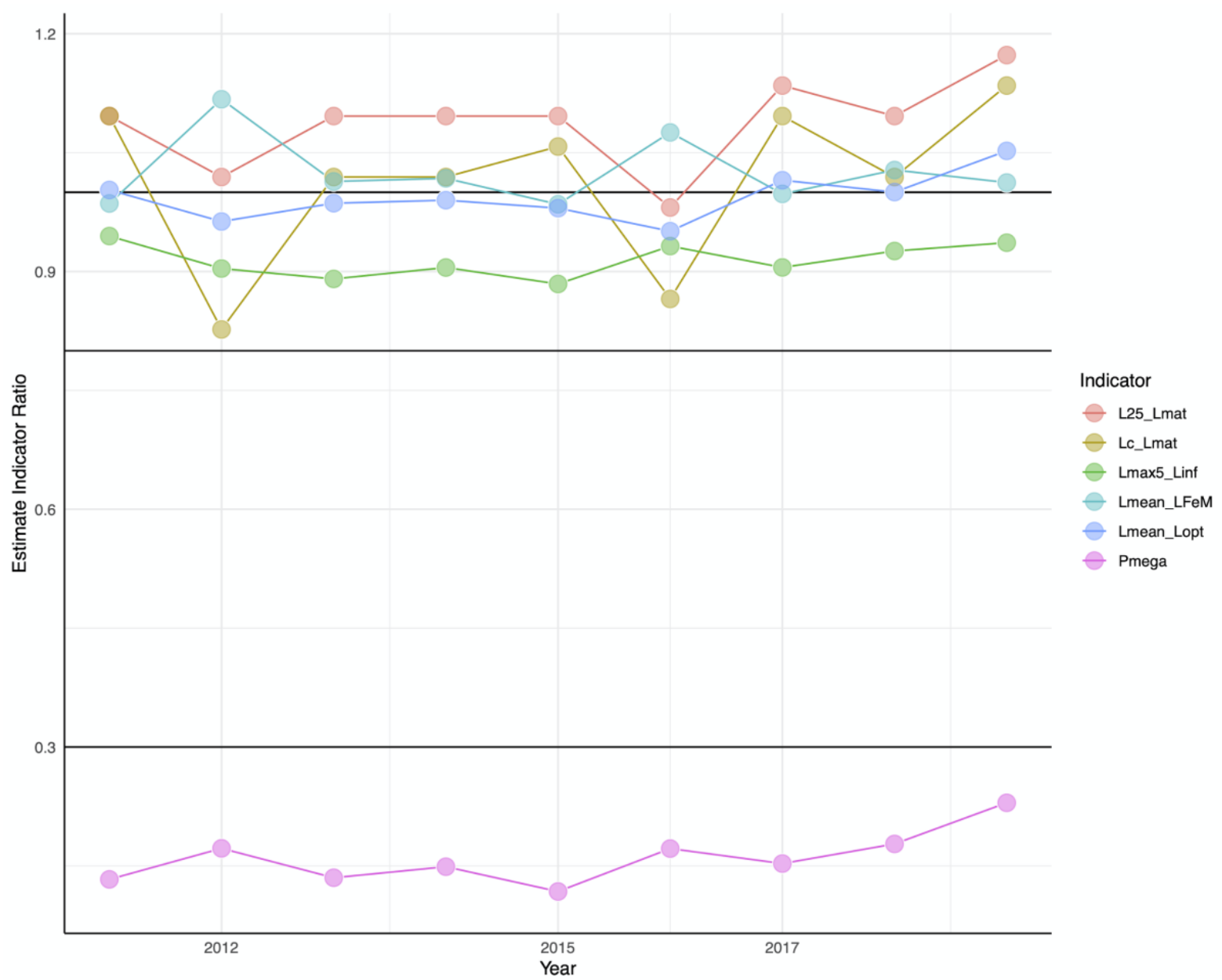

Figure 2: Temporal trends of the LBI indicator ratios estimates derived from the base model. Horizontal lines at reference values of $0.3,0.8$ and 1 are included. Note that Pmega must be above 0.3 , the expected value of $\mathrm{Lmax}_{5} \% / \mathrm{L} \infty$ is above 0.8 , and $\mathrm{Lc} / \mathrm{Lmat}, \mathrm{L} 25 \% / \mathrm{Lmat}$, Lmean $/ \mathrm{Lopt}_{\text {, and }}$ $\mathrm{Lmean} / \mathrm{LF}=\mathrm{M}$ are expected to be higher than 1 or closed to it. 


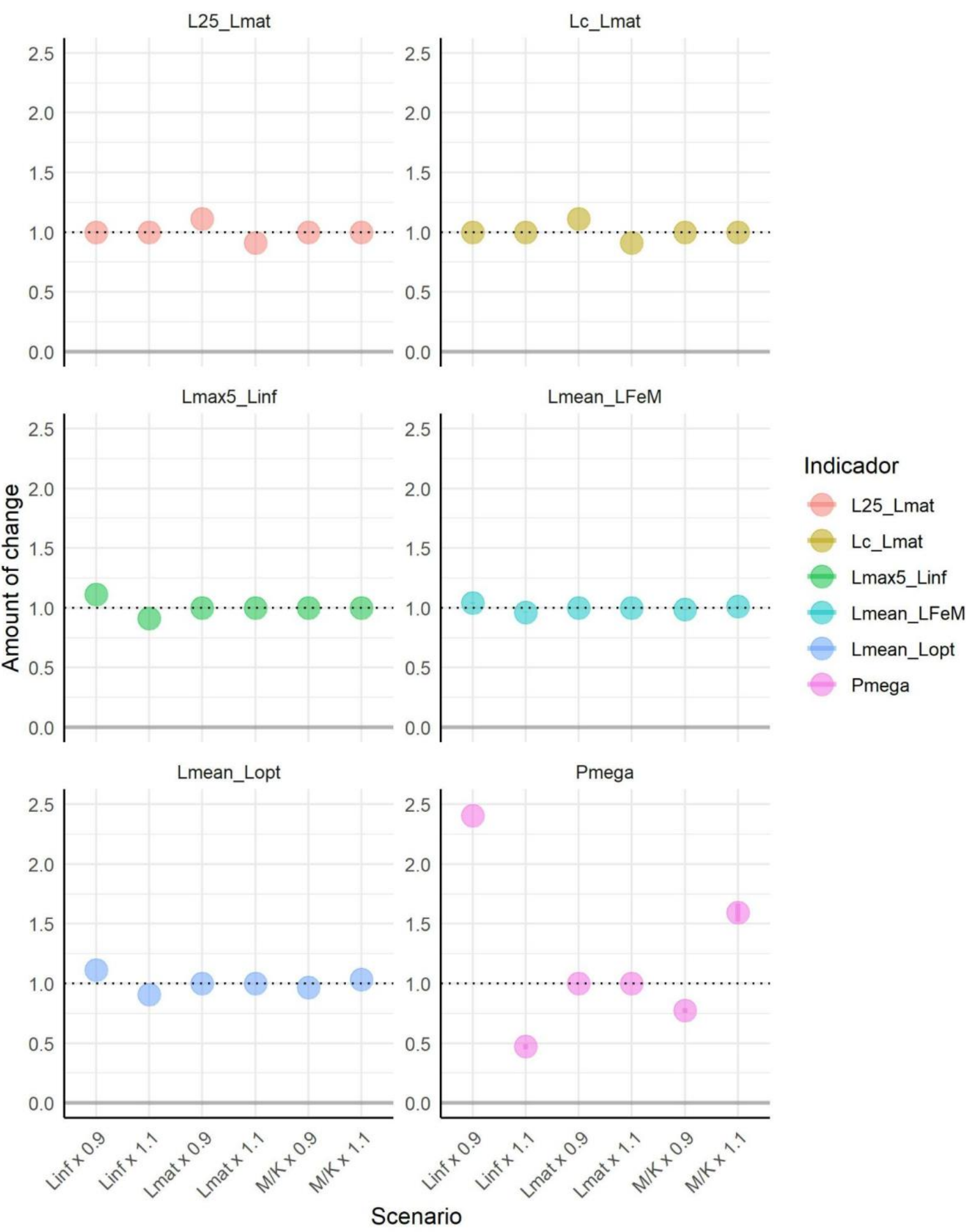

Figure 3: LBI sensitive analysis using underestimation and overestimation of $\mathrm{L}_{\infty}, \mathrm{M} / \mathrm{K}$ and $\mathrm{L} 50$ parameters at the $10 \%$ of the reference model values. For each setting, the annual average of ratios change, defined as the mean of the annual vector of ratios of the values of the indicator in the corresponding setting over such values in the reference setting, is plotted as a point. Furthermore, the associated standard deviation is represented through a horizontal line whose 764 extremes are the mean minus the standard deviation and plus such quantity. 


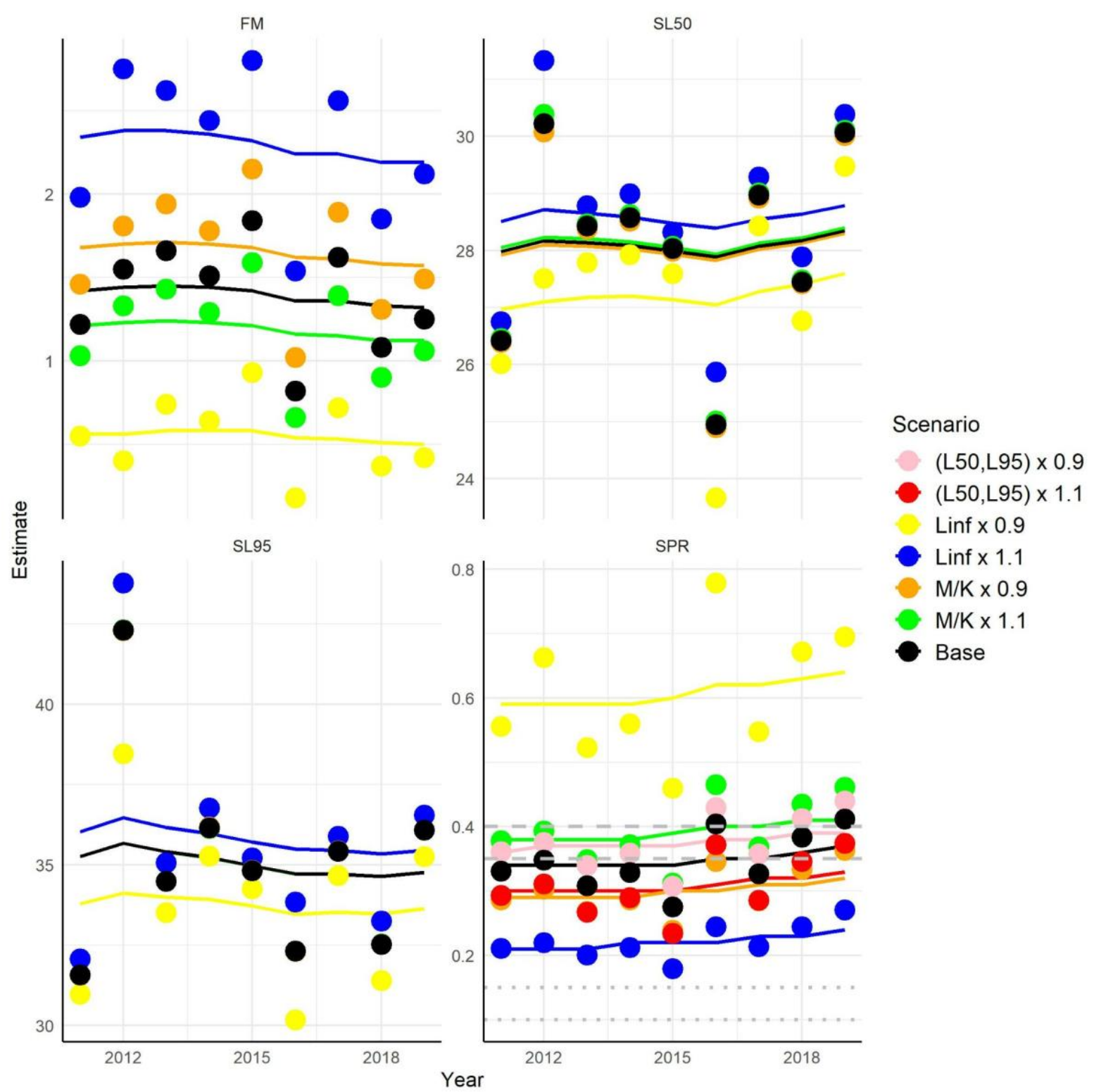

Figure 4: LBSPR results (F/M, SPR, L50 and L95) for the base model and sensitive analysis scenarios of the common sole stock. LBSPR sensitive analysis was performed using the underestimation and overestimation of $\mathrm{L}_{\infty}, \mathrm{M} / \mathrm{K}, \mathrm{L}_{50}$ and $\mathrm{L}_{95}$ parameters at the $10 \%$ of the reference model values. In the F/M plot the results of the overestimation and underestimation of L50 and L95 overlap the reference scenarios. In SPR plot horizontal dashed lines delimit the range where the stock is considered at MSY level, whereas horizontal dotted lines show the levels below which the stock is considered collapsed. 


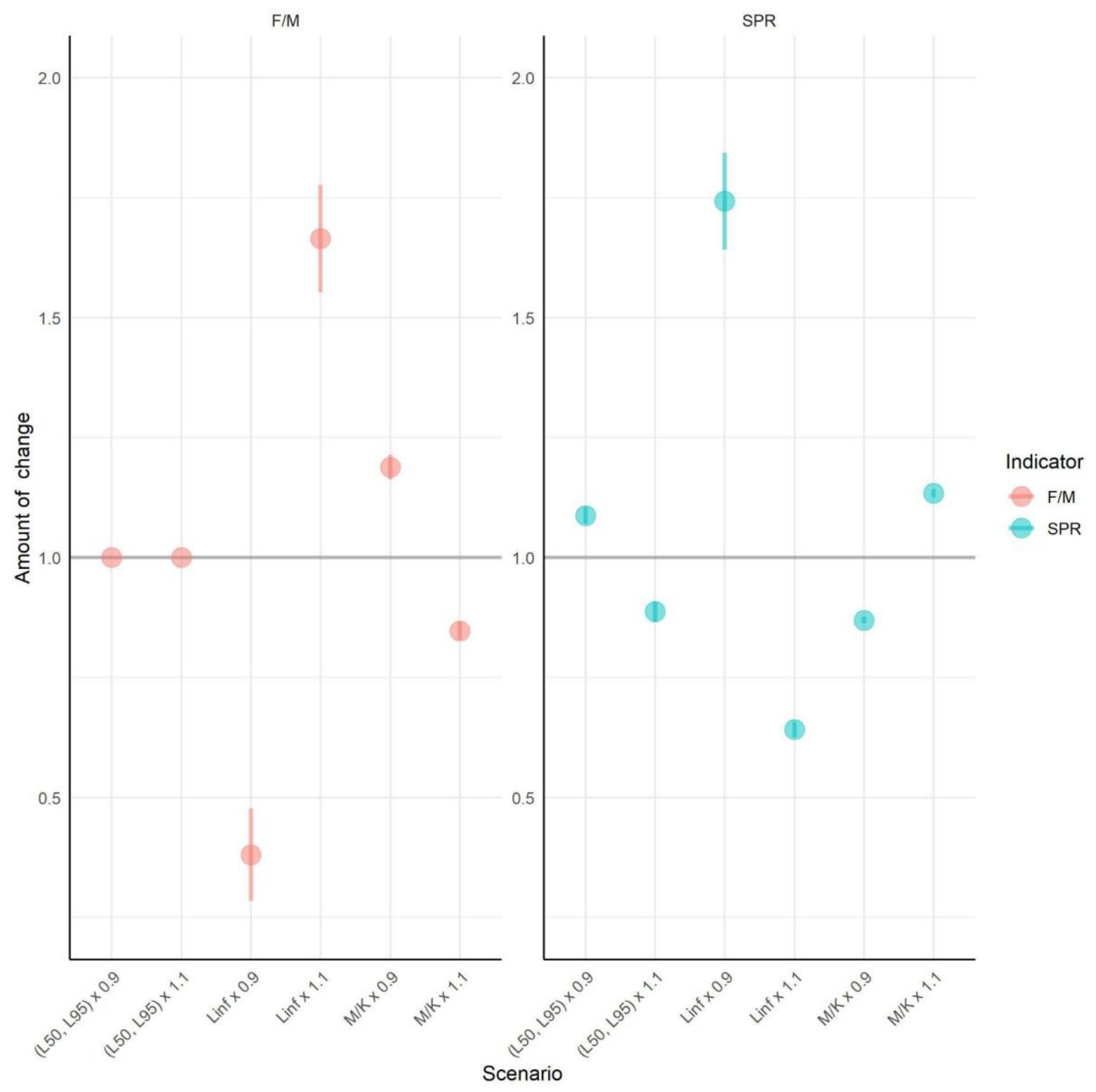

Figure 5: LBSPR sensitive analysis using underestimation and overestimation of $\mathrm{L}_{\infty}, \mathrm{M} / \mathrm{K}, \mathrm{L} 50$ and L95, parameters at the $10 \%$ of the reference model values. For each setting, the annual average of the ratios change, defined as the mean of the annual vector of ratios of the values of SPR (or F/M) estimates in the corresponding setting over such values in the reference setting, is plotted as a dot. Furthermore, the associated standard deviation is represented through a vertical line whose extremes are the mean minus the standard deviation and plus such quantity. 

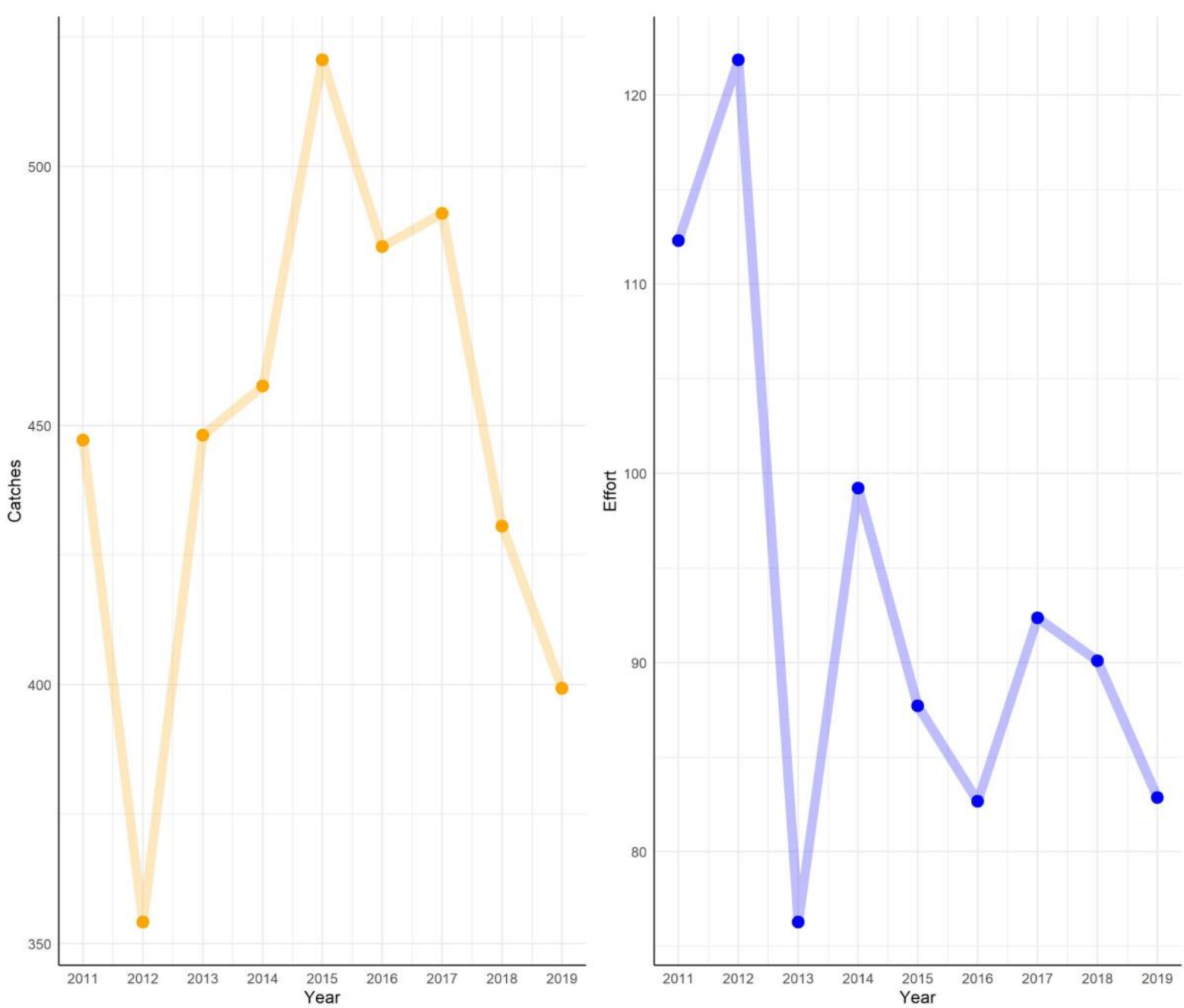

Figure 6. Catches and effective effort index used in the MLZ model for the common sole from 8042011 to 2019 in the Portuguese waters (Division 9a).

805

806

807

808

809

810

811

812

813

814

815

816

817

818

819 


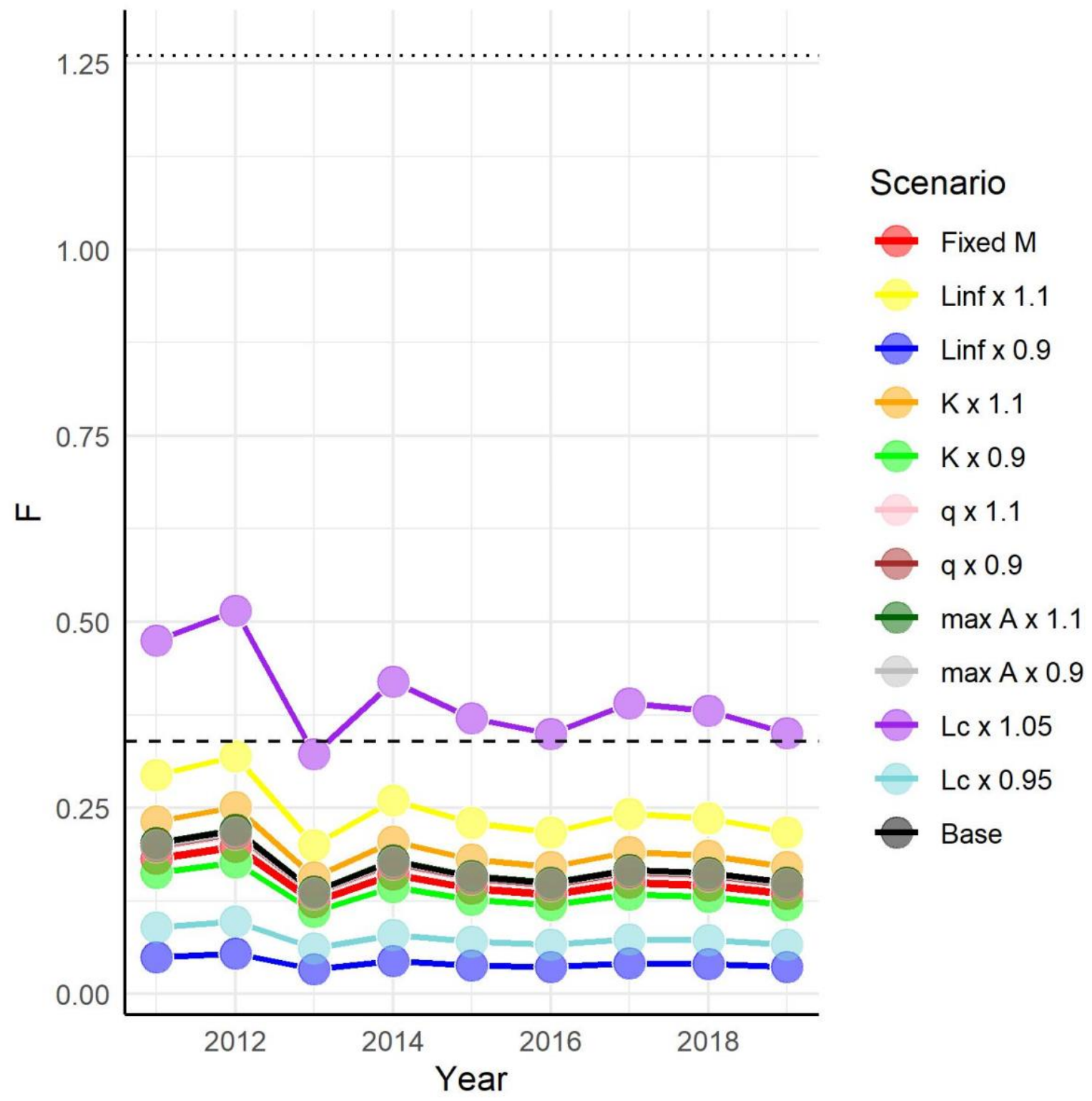

Figure 7: F estimates derived from MLZ method in the base setting and sensitive analysis scenarios for the common sole stock. MLZ sensitive analysis was performed using the underestimation and overestimation of $\mathrm{L}_{\infty}$ and $\mathrm{K}$ parameters and maximum age (max A) and $\mathrm{q}$ guesses at the $10 \%$ of the base model values, whereas such percentage was $5 \%$ for the sensitive analysis of the $\mathrm{L}_{c}$ parameter. In all settings, in the base one and in the sensitivity analysis settings mentioned above, the natural mortality rate (M) was estimated, for comparative purposes, the graph also includes the $\mathrm{F}$ estimates corresponding to the reference model but fixing $M$ equal to 0.31 . $F_{\max }$, the value of fishing mortality that produces maximum YPR (Yield-per-Recruit), is represented by a dotted horizontal line. $\mathrm{F}_{0.1}$, the value of fishing mortality at which the slope of the YPR curve is reduced to 0.1 of that estimated at the origin, is represented by a horizontal dashed line. 
$\mathrm{F}$
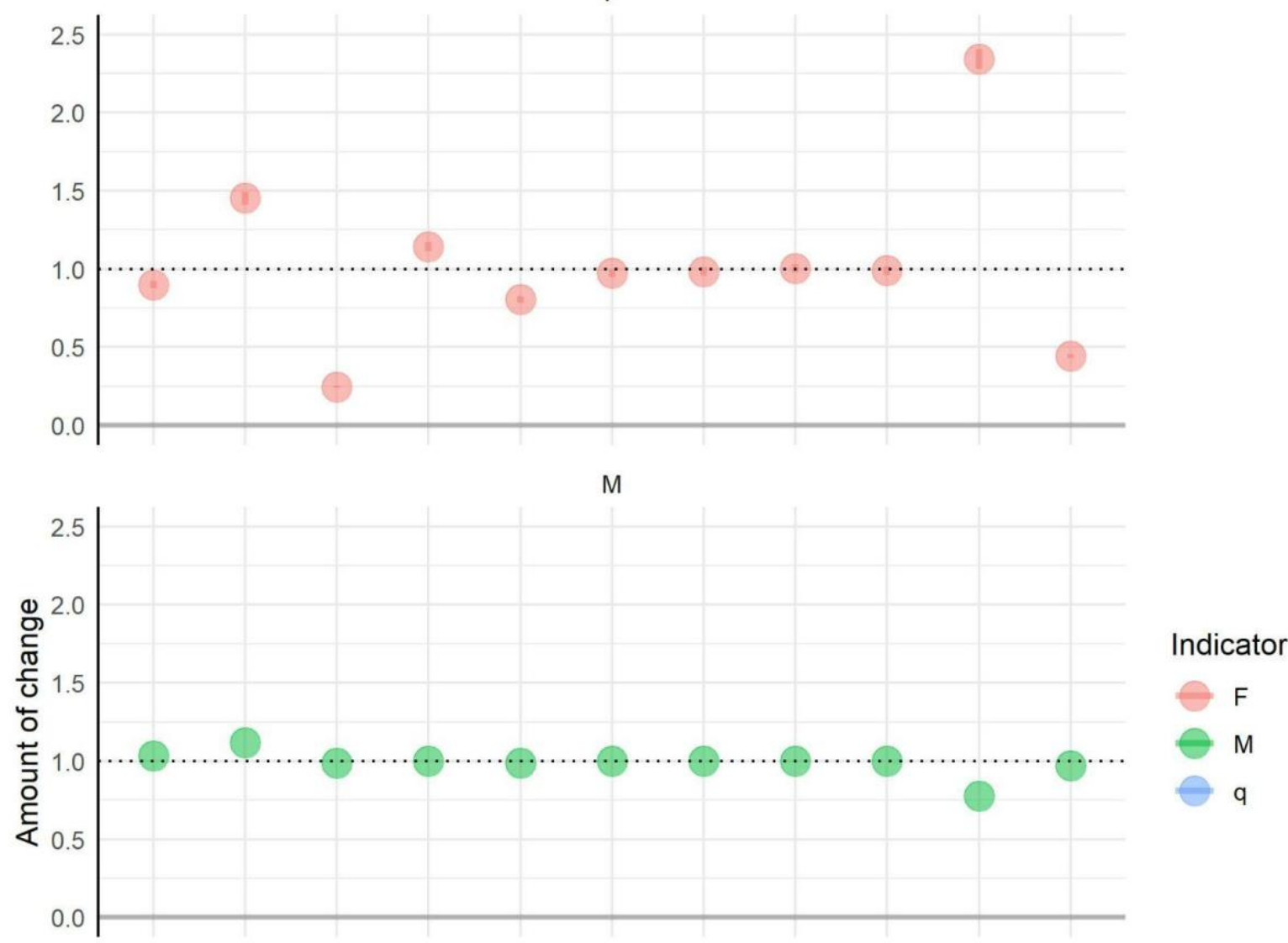

q

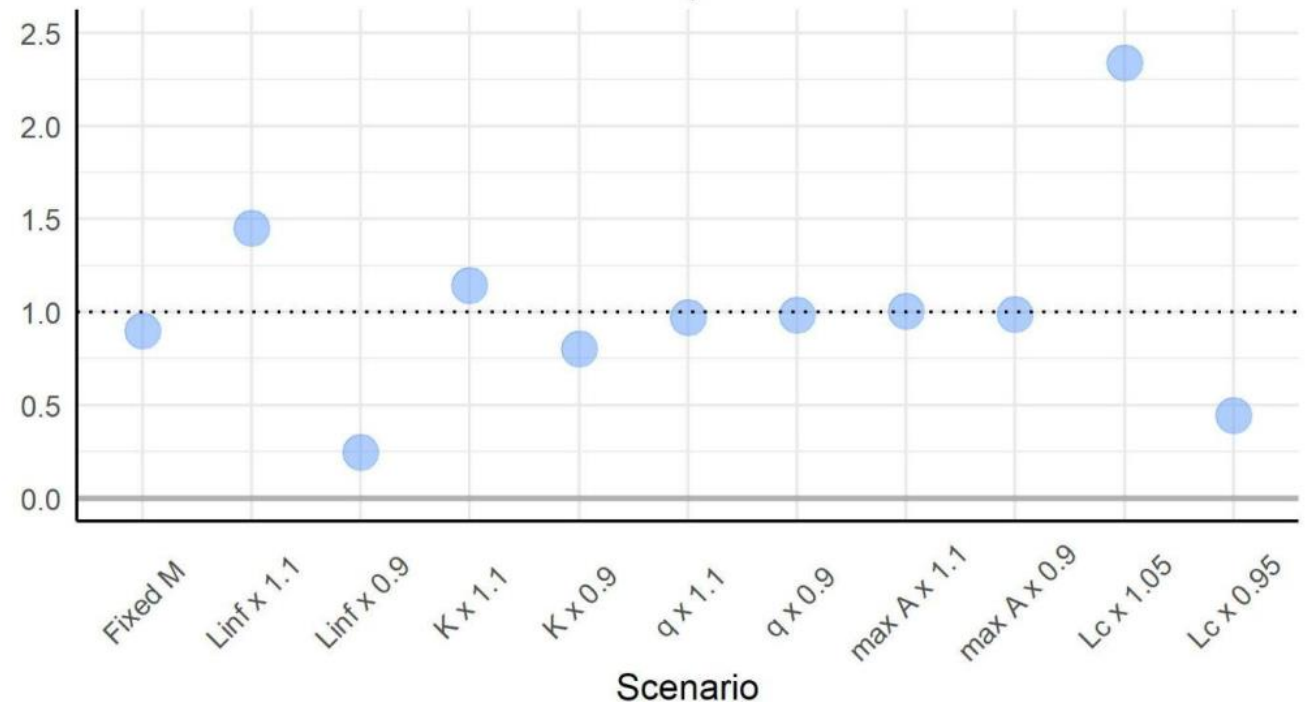

Scenario

838 Figure 8: MLZ sensitive analysis using underestimation and overestimation of $\mathrm{L}_{\infty}$ and $\mathrm{K}$ 839 parameters, and maximum age ( $\max A$ ) and q guesses at the $10 \%$ of the base model values, 840 whereas such percentage was $5 \%$ for the sensitive analysis of the $\mathrm{L}_{\mathrm{c}}$ parameter. In all settings, 841 the natural mortality rate $(\mathrm{M})$ was estimated, for comparative purposes, the graph also includes 842 the setting corresponding to fix $M$ equal to 0.31 . For each setting, the annual average of ratios 843 change, defined as the mean of the annual vector of ratios among the $F$ values in the 844 corresponding setting and such values in the reference setting, is plotted as a dot. Furthermore, 845 the associated standard deviation is represented through a horizontal line whose extremes are 846 the mean minus the standard deviation and plus such quantity. For $\mathrm{M}$ and q, the ratios among 
847 their values in the corresponding setting and such values in the reference setting are plotted as 848 a dot.

849

850

851

852 